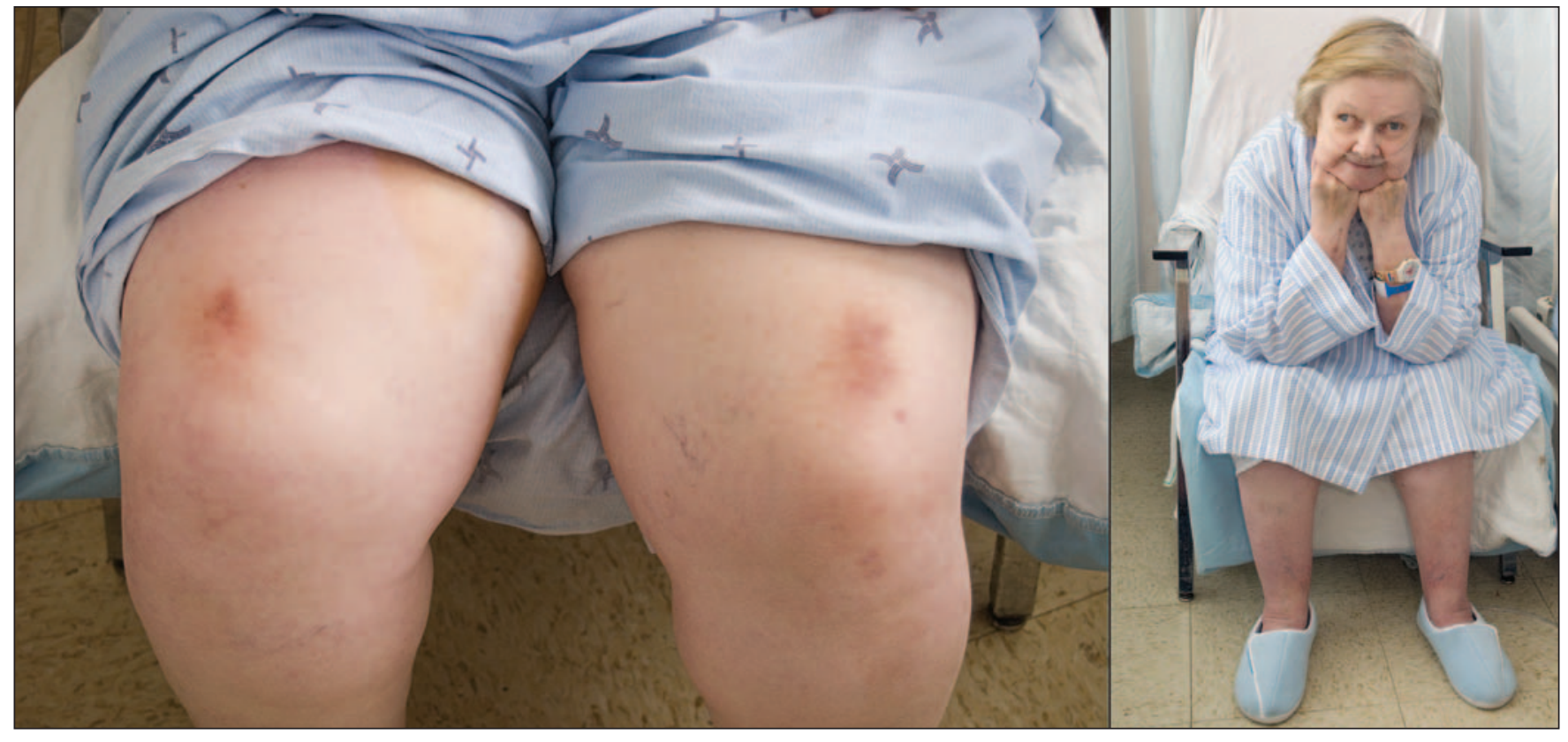

Figure 1: A 73-year-old woman with circular, bilateral, hyperkeratotic skin patches above both knees (left). These patches may develop when patients spend long periods of time in the "thinker's position" (right).

\section{The thinker's sign}

$\mathrm{T}$ his patient presented with tachypnea and use of the inspiratory accessory muscles. Chest auscultation revealed diffusely decreased air entry bilaterally and early inspiratory rales. A chest radiograph showed hyperinflation and increased radiolucency of the lungs. The results of pulmonary function tests were consistent with severe airflow obstruction that did not respond to bronchodilators (forced expiratory volume in the first second of expiration $\left[\mathrm{FEV}_{1}\right] 29 \%$ predicted). On physical examination, we noticed circular, bilateral, hyperkeratotic skin patches above both knees (Figure 1).

These lesions, also known as the "thinker's sign," arise from irritation of the skin caused $\therefore$ by pressure from the elbows in patients who spend long periods of time in the tripod position (Figure 1). The braced body position, a nonspecific finding in respiratory distress, maximizes effectiveness of the accessory muscles of inspiration. Leaning forward also increases intra-abdominal pressure, allowing the flattened diaphragm to regain its natural shape and its ability to function as a piston. ${ }^{2}$ Although it is most often observed in severe obstructive lung disease $\left(\mathrm{FEV}_{1}<30 \%\right.$ predicted), this sign can be seen in other conditions where respiratory distress occurs, including congestive heart failure.
Clinical images are chosen because they are particularly intriguing, classic or dramatic. Submissions of clear, appropriately labelled high-resolution images must be accompanied by a figure caption and the patient's written consent for publication. A brief explanation (300 words maximum) of the educational significance of the images with minimal references is required.
Gabriel Rebick MD

Department of Medicine Weill Cornell Medical Center

New York, NY

Suzanne Morin MD MSc

Department of Medicine

McGill University

Montréal, Que.

\section{REFERENCES}

1. Rothenberg HJ. The thinker's sign. JAMA 1963;184:902-3.

2. Sapira JD. The art and science of bed side diagnosis. Baltimore (MD): Urban and Schwarzerberg; 1990. 